\title{
Optimization of HPLC conditions for quantitative analysis of aflatoxins in contaminated peanut.
}

\begin{abstract}
The main objective of present study was to investigate the effect of HPLC conditions namely mobile phase composition (X1), flow rate (X2) and temperature (X3) on peak area of four target aflatoxins (i.e. B1 (Y1), B2 (Y2), G1 (Y3) and G2 (Y4)) from the spiked peanut. The significant nonlinear response surface models with high coefficient of determinations (R2) ranging from 0.958 to 0.995 were fitted to evaluate the detection value of target aflatoxins as a function of HPLC variables. Flow rate had the most significant ( $p<0.05)$ effect on quantification value of target aflatoxins. The highest quantification value for target aflatoxins could be obtained under the following HPLC conditions: the mobile phase composition of $\mathrm{ACN} / \mathrm{H} 2 \mathrm{O} / \mathrm{MeOH}: 8 / 54 / 38$, temperature of $24{ }^{\circ} \mathrm{C}$ and flow rate of $0.4 \mathrm{~mL} / \mathrm{min}$. The recommended optimum HPLC conditions provided higher peak area for all target aflatoxins by 1-2.5 fold compared to two other conditions (A: mobile phase (ACN/H2O/MeOH: 23/54/23), ambient temperature $\left(28-32{ }^{\circ} \mathrm{C}\right)$, flow rate $1 \mathrm{~mL} / \mathrm{min} ; \mathrm{B}$ : mobile phase (ACN/H2O/MeOH: $17 / 54 / 29$ ), temperature $30^{\circ} \mathrm{C}$, flow rate $1 \mathrm{~mL} / \mathrm{min}$ ).
\end{abstract}

Keyword: Aflatoxin; Detection value; Flow rate; High pressure liquid chromatography; Mobile phase; Peanut; Response surface methodology. 